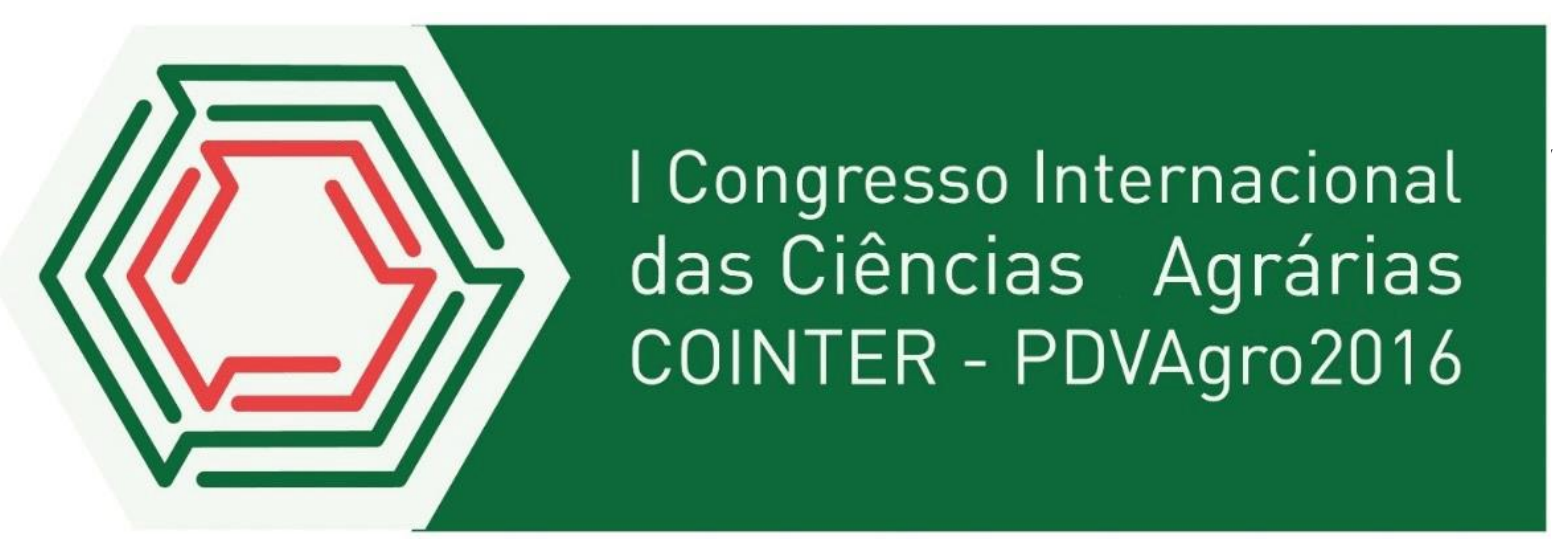

\title{
MODELO DE GESTÃO COOPERATIVISTA: UM ESTUDO NA COOPERATIVA DE EDUCAÇÃO DA UNIVERSIDADE FEDERAL DA PARAÍBA - UFPB
}

\author{
Apresentação: Comunicação Oral \\ Elenice da Silva Moraes ${ }^{1}$; Íris Moura de Pontes²; Luana Patrícia da Silva ${ }^{3}$; Luan Allison Félix \\ de Oliveira ${ }^{4}$; Telma Lúcia de Andrade Lima ${ }^{5}$
}

\section{Resumo}

As cooperativas trazem consigo grandes influências no desenvolvimento do trabalho cooperativo e na responsabilidade social. Isto se deve a legalidade e existências dos princípios cooperativistas: (1) Adesão Livre e Voluntária, (2) Gestão Democrática, (3) Participação Econômica, (4) Autonomia e Independência, (5) Educação, (6) Inter Cooperação, (7) Interesse pela Comunidade, estes preservam a identidade cooperativista. É de suma importância para toda e qualquer organização que se utilize um modelo de gestão para desenvolver e operacionalizar as atividades de planejamento, organização, direção e avaliação. Diante do exposto, esta pesquisa tem como objetivo identificar o modelo de gestão da CODISMA, Cooperativa de Educação da Universidade Federal da Paraíba - UFPB. O qual pretende responder a seguinte questão-problema: Qual modelo de gestão adotado pela cooperativa? A CODISMA surgiu em 1962 como cooperativa cultural e distribuidora de material escolar da UFPB de responsabilidade LTDA. Inicialmente tinha por objetivo adquirir livros dos cursos de medicina e direito, e fornecera-los a preço de custo aos estudantes universitários. Para o estudo foi aplicada uma pesquisa qualitativa de caráter exploratório e explicativa. De acordo com Vergara (2007) a pesquisa explicativa tem como principal objetivo tornar as ações estudadas em dados de fácil compreensão, justificando e explicando os seus principais motivos e o "por que" das coisas. O resultado extraído da pesquisa mostra que a cooperativa apresenta um delineamento das autoridades em cada unidade organizacional, sendo definido os níveis hierárquicos e departamentais, relatado pela Assessora da Cooperativa, que são: Secretaria, Coordenação dos cursos de idiomas, Coordenação de marketing, Assessoria de comunicação, Assessoria jurídica, Assessoria cooperativista, Cultura e técnico científico, Diretoria executiva, Conselho de administração e Conselho fiscal. A CODISMA enfrentou várias mudanças, desde a localidade, até deixar de ser livraria para focar no ensino de idiomas, conseguindo assim, resistir a todas as mudanças pela qual passou. Ao ser analisado o modelo de gestão adotado pela Cooperativa, observou-se que a mesma adota de maneira

\footnotetext{
1 Programa de Pós-Graduação em Administração e desenvolvimento Rural, Universidade Federal Rural de Pernambuco, elenicemoraes7@gmail.com

2 Administração, Universidade Federal da Paraíba, irispontesadm1 @ gmail.com.

3 Administração, Universidade Federal da Paraíba, admluanapatricia@gmail.com.

${ }^{4}$ Administração, Universidade Federal da Paraíba, luallys2306@gmail.com

${ }^{5}$ Doutora, Universidade Federal rural de Pernambuco, tlima.ufrpe@gmail.com.
} 
concreta o modelo de gestão proposto por Oliveira (2006) o qual propõe uma estrutura geral da gestão da cooperativa, dividindo-se em componentes estratégicos, estruturais, diretivos, tecnológicos, comportamentais, mudanças e avaliação.

Palavras-Chave: Cooperativismo; Modelo de Gestão; Administração

\section{Introdução}

No século XVIII com o advento da Revolução Industrial na Inglaterra a mão de obra perdeu grande poder de sua fonte de renda, a partir dessa ocasião surgiram lideranças que concluíram que com a organização formal chamada cooperativa era possível superar as dificuldades. Em 1844 em Rochdale foi criada a primeira cooperativa de consumo. "Considera-se as organizações cooperativas como viáveis para o sucesso do desenvolvimento socioeconômico com expressiva contribuição para o crescimento do volume de emprego e renda" (ROSSÉS et al, 2010). As cooperativas são grandes forças de trabalho e também de responsabilidade social, seguindo sempre um conjunto de princípios e valores para assim manter a sua identidade.

Diante das transformações da sociedade e com a nova realidade econômica, o sistema capitalista toma maior parte da economia, o sistema cooperativista luta para conseguir se manter e preservar suas características, seus princípios e valores. Segundo Oliveira (2006), a atual realidade da economia tem levado as empresas do mercado seja ela uma cooperativa ou não, a desenvolverem novos modelos de gestão que utilizem modernos instrumentos

administrativos. É de suma importância para toda e qualquer organização a utilização de um modelo de gestão para desenvolver e operacionalizar as atividades de planejamento, organização, direção e avaliação.

Esta alternativa a economia desenvolveu-se no século XXI o cooperativismo operário como principal antecedente, o qual surgiu durante o século XIX, como reação à Revolução Industrial, uma tentativa de construir outra maneira de organizar a economia, com base no trabalho associado e na distribuição equitativa do excedente adquirido e não na acumulação individual do dinheiro a partir da exploração do trabalho alheio.

De acordo com Maraschin (2004) apud Rossés et al, (2010), as cooperativas surgem como uma oportunidade e alternativa a autogestão, melhorando as condições dos produtores frente ao poder de mercado, cada vez mais competitivo. Para o sistema cooperativista, o modelo de gestão torna-se uma ferramenta fundamental para administrar suas atividades e obter bons desempenhos, pois assim poderá manter-se ativa no mercado e sendo competitiva perante o mesmo. As cooperativas enfrentam grandes desafios perante o mercado em que 
atuam, por isto, é vital para a permanência no mercado e adoção de um sistema de gestão efetivo sendo fundamental para o bom desempenho de suas atividades.

Diante do exposto, essa pesquisa tem o objetivo de identificar o modelo de gestão da CODISMA, Cooperativa de Educação da Universidade Federal da Paraíba - UFPB. O qual pretende responder a seguinte questão-problema: A cooperativa CODISMA adota algum modelo de gestão?

\section{Fundamentação Teórica}

As cooperativas para que possam existir devem seguir alguns princípios. Segundo Crúzio (2005, p. 68), Matos (2005, p. 253) e Oliveira (2006, p. 83) trazem sete princípios que devem existir nas cooperativas, sendo eles: (1) Adesão Livre e Voluntária, (2) Gestão Democrática, (3) Participação Econômica, (4) Autonomia e Independência, (5) Educação, (6) Inter Cooperação, (7) Interesse pela Comunidade, instituídos pela Internacional Co-operative Alliance (ICA), tais princípios são abordados com ênfase, importância e prática da autogestão.

O primeiro princípio a Adesão Livre e Voluntária, segundo Crúzio (2005, p. 68), Matos (2005, p. 253) e Oliveira (2006, p. 83) as cooperativas são organizações voluntárias, abertas a qualquer indivíduo aptos a usar serviços e dispostas a aceitar as responsabilidades de sócio colaborador. Isto implica dizer que qualquer pessoa pode aceitar e se dispor a participar de determinada cooperativa e seguir o conselho presentes em seu regimento e no que reza a lei.

O princípio Gestão Democrática ou sequencial é o que diz respeito à participação na através da interferência administrativa dos sócios. Os autores Crúzio (2005, p. 68), Matos (2005, p. 253) e Oliveira (2006, p. 83), destacam que as cooperativas são empresas democráticas, na qual os sócios integrantes participam e estabelecem conjuntamente o planejamento, políticas e sobre o funcionamento da empresa, através do voto, cada membro tem o poder de um voto, sem favoritismo para nenhum cooperado, pois todos são iguais perante a cooperativa.

O terceiro princípio é a participação econômica dos sócios, os quais cooperam igualitariamente e controlam democraticamente o capital de todos os membros, pois tudo é propriedade comum de suas cooperativas e cooperados. De acordo com os autores Crúzio (2005, p. 68), Matos (2005, p. 253) e Oliveira (2006, p. 83), ressaltam que os sócios destinam as sobras ao desenvolvimento da própria cooperativa, o que possibilita a formação de reservas financeiras para novos investimentos. 
No princípio da autonomia, segundo Crúzio (2005, p. 68), Matos (2005, p. 253) e Oliveira (2006, p. 83), baseia-se na ideia de que as cooperativas são organizações autônomas de ajuda mútua, controladas por seus membros. Mesmo que a cooperativa firme acordos com outras organizações, deve-se manter viva e atuante a autonomia e seguindo arisca os principios.

As cooperativas proporcionam, segundo o quinto princípio a educação e treinamento aos sócios partícipes, dirigentes eleitos, administradores e funcionários, de modo a contribuir efetivamente para o seu desenvolvimento e sustentabilidade, exibido por Crúzio (2005, p. 68), Matos (2005, p. 253) e Oliveira (2006, p. 83). De acordo com este preceito, a administração da cooperativa deve informar ao público, sobre a natureza e os benefícios de ser integrante de uma organização cooperativa.

$\mathrm{Na}$ Inter cooperação exposto no sexto princípio, as cooperativas atendem a seus sócios mais efetivamente e fortalecem o movimento cooperativo trabalhando unidas a outras de forma a dividir as boas experiências e os bons resultados, pois todos deve crescer juntos para o movimento não parar (CRÚZIO, 2005, p.68); (MATOS, 2005, p.253); (OLIVEIRA, 2006, p.83).

Por último, o princípio defendido nas obras de Crúzio (2005, p. 68), Matos (2005, p. 253) e Oliveira (2006, p. 83), afirma existência da preocupação com a comunidade, através dela, as cooperativas trabalham pelo desenvolvimento sustentável de suas comunidades nas quais se localizam, através de políticas aprovadas pela maioria de seus membros. Estes princípios norteiam a administração de cooperativas servindo como instrumento legal e dando uma maior credibilidade ao setor, fazendo com que haja uma padronização e uma base para a administração de cooperativas no país. Diante disso, percebe-se que tais princípios são de fundamental importância para seguir o modelo de Gastão proposto por Oliveira.

Segundo Oliveira (2006) "o modelo de gestão pode ser conceituado como processo estruturados, interativo e consolidado de desenvolver e operacionalizar as atividades de planejamento, organização, direção e avaliação dos resultados, visando ao crescimento e ao desenvolvimento da cooperativa". Oliveira (2006) propõe uma estrutura geral do modelo de gestão das cooperativas que se dividem em componentes estratégicos, estruturais, diretivos, tecnológicos, comportamentais, mudanças, e por último de avaliação. Pode ser visto na figura abaixo a estrutura completa, seus componentes e seus indicadores.

O primeiro componente administrativo trata-se do Estratégico, no qual Oliveira (2006) considera que para se alcançar a eficiência e a eficácia dos negócios, o planejamento Estratégico é o processo administrativo que constrói a direção e as metas das cooperativas, a 
direção a ser seguida e alcançado, para a obtenção das metas, levando em consideração as variáveis do meio externo.

Figura 1: Modelo de Gestão de Cooperativas e seus componentes

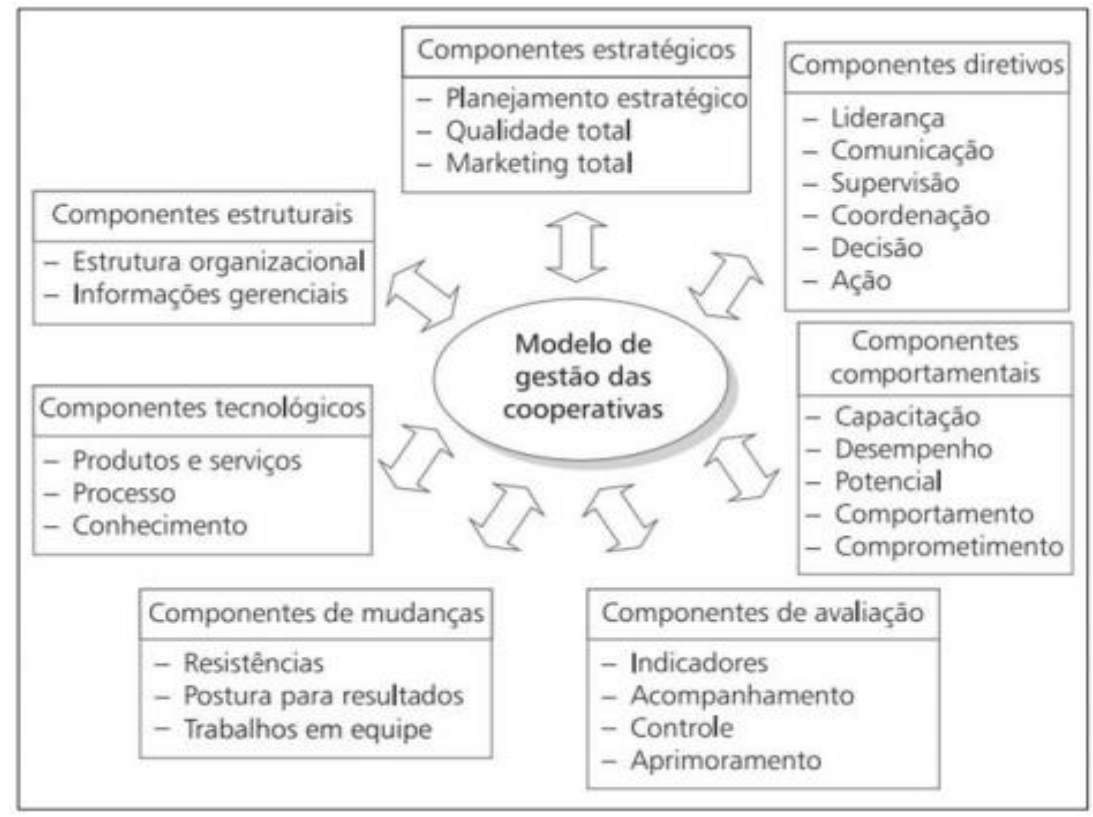

Fonte: OLIVEIRA (2006, p. 40).

O segundo componente administrativo aborda os componentes Estruturais. De acordo Com Oliveira (2006) pode ser entendido que uma estrutura organizacional considera a delegação de tarefas, funções e responsabilidades em diferentes níveis da administração e a relação de cada parte com as demais e com a cooperativa como um todo.

Os componentes diretivos referem-se ao terceiro componente, com base no modelo de Gestão, Oliveira (2006) afirma que: os componentes diretivos consideram a comunicação como o processo de entendimento e transmissão de um dado ou informação que ocorre entre emissor e receptor visando alguma finalidade da cooperativa. Quando o administrador toma uma decisão, dentre as informações disponíveis, o caminho que a cooperativa irá seguir para alcançar o resultado esperado, será preciso ação, assim implementando a decisão tomada, utilizando de recursos disponíveis para obtenção do resultado planejado pela a cooperativa.

O quarto componente destacam-se os componentes tecnológicos. Conforme Oliveira (2006), os produtos e serviços oferecidos aos consumidores, devem levar em consideração a relação cooperativo/cooperado/mercado, em que se trata do objetivo para existência da organização cooperativa, deve ser também ser desenvolvido por um conjunto de atividades 
sequenciais relacionadas que busca atender às necessidades dos clientes, cooperados e funcionários da cooperativa.

Os componentes comportamentais fazem parte do quinto componente administrativo, no qual Oliveira (2006) o define como sendo: a capacitação tanto para se aprender com o para aplicar conhecimentos nas atividades desenvolvidas pela cooperativa e seus cooperados; o desempenho a consideração do esperado e estabelecido para uma atividade ou cargo em relação aos resultados obtidos pelo funcionário responsável pela função; o potencial como conjunto de características e conhecimentos que determinada pessoa apresenta para exercer alguma atividade relacionada ou não à sua função ou cargo; o comportamento como resultado em atitudes de determinado indivíduo que sofre influência de diversas variáveis do ambiente que o cerca; e o comprometimento na forma de aceite da responsabilidade para alcançar os objetivos da cooperativa ou dos cooperados.

O sexto componente administrativo são os de mudança, para Oliveira (2006) a administração de resistências é o fator que identifica a conjugação dos valores e expectativas dos funcionários da cooperativa, tentando diminuir algum tipo de dificuldade encontrada no processo de evolução da organização por meio de orientação e capacitação bem como o entendimento da validação dos resultados. Para o alcance dos objetivos elaborados pela cooperativa usa-se a postura para os resultados direcionando os recursos humanos e financeiros disponíveis. Assim, sendo apoiados a isso, o trabalho em grupo é usado para desempenhar as atividades de maneira conjunta, unindo o treinamento e aprendizagem.

E por último, os componentes de avaliação, na visão de Oliveira (2006) sendo considerados como indicadores de desempenho, utilizados como parâmetros de avaliação préestabelecidos que permitem medir o grau de sucesso na realização das atividades ou processos da cooperativa.

\section{Metodologia}

A Caracterização da pesquisa, segundo (GIL, 2010), toda pesquisa de caráter cientifico se utilizam de técnicas e métodos para ajudar no processo de investigação de seu objeto. Se faz necessário inicialmente, definir os instrumentos da pesquisa por intermédio de um planejamento prévio.

Foi aplicado uma pesquisa qualitativa de caráter exploratório e explicativa. De acordo com Vergara (2007) "a pesquisa explicativa tem como principal objetivo tornar as ações estudadas em dados de fácil compreensão, justificando e explicando os seus principais motivos e o "por que" das coisas". 
Normalmente a pesquisa qualitativa implica a construção de inquéritos por roteiro de entrevista. São contatadas muitas pessoas. O objeto de pesquisa também é um estudo de caso. Segundo Gil (2008) “ o estudo de caso é caracterizado pelo estudo profundo e exaustivo de um ou de poucos objetos, de maneira a permitir o seu conhecimento amplo e detalhado, tarefa praticamente impossível mediante outros tipos de delineamento considerado", corroborando com isso, de acordo com Yin (2005, p.32) apud Gil (2008), “o estudo de caso é um estudo empírico que investiga um fenômeno atual dentro do seu contexto de realidade, quando as fronteiras entre o fenômeno e o contexto não são claramente definidas e no qual são utilizadas várias fontes de evidencia". Logo, foi-se aplicado um roteiro de entrevista com a assessora de comunicação que contribuiu com as respostas.

O Ambiente da pesquisa foi na CODISMA (Cooperativa Cultural Universitária da Paraíba), a qual é uma cooperativa no ramo da educação, e consolida junto aos serviços de livraria, vídeo-locadora, eventos culturais, convênio para venda de material escolar, além de oferecer cursos de Idiomas. E chamou nossa atenção pelo fato de ajudar as pessoas a aprenderem outras línguas e aprimorarem seus conhecimentos.

A CODISMA surgiu em 1962 como cooperativa cultural e distribuidora de material escolar da UFPB de responsabilidade LTDA. Inicialmente tinha por objetivo adquirir livros dos cursos de medicina e direito, que eram muito caros, e fornecer a preço de custo aos Estudantes universitários. Na década de 90 passou por uma mudança estatutária, desvinculando-se da UFPB, passando a se chamar Cooperativa Cultural Universitária da Paraíba. A mesma é composta por 367 servidores da UFPB e 1536 alunos de idiomas.

Os seus representantes legais são: Presidente: Sebastiao Geriz Sobrinho; VicePresidente: Severino Ramos Mendonça de Santana (afastado) e Abdias de Luna Freire de Medeiros (em exercício); Secretário executivo: Evanilda dos Santos Silva; Conselheiro: Agamenon Travassos Sarinho; Conselheiro: Rosilda Vicente do Nascimento; Conselheiro: Marcos da Paz Figueiredo.

Os cursos de Idiomas oferecidos pela cooperativa são: Inglês; Espanhol; Português; Francês; Alemão; Italiano e Russo, Português para concurso, Pro eficiência e Raciocínio Lógico. E também cursos de extensão em várias áreas de conhecimento, como: Marketing Político; Elaboração de Projetos de Pesquisa em Monografia; Redes Sociais; Violão clássico e popular; Cooperativismo; Xadrez; Desenvolvimento Sustentável; Jardinagem; Paisagismo; Associativismo; Produção de TV e Gestão. A CODISMA divulga a cultura do Estado da Paraíba, apoiando, cooperando e vendendo trabalhos de artistas, sejam eles músicos, pintores, cordelistas, atores, cantores, produtores, artesões, entre outros. 
Instalada originalmente no centro da cidade de João Pessoa, desde agosto de 1962, encontrou espaço propício no Campus I da UFPB, tendo também um anexo fora da Universidade, onde como cooperativa distribuidora de material escolar, passa a contribuir com facilidades de preços de livros e material escolar para os seus associados (estudantes, funcionários e professores da UFPB).

\section{Resultados e Discussão}

De acordo com os dados coletados a partir da entrevista com a assessora de comunicação da CODISMA, pode-se observar que a cooperativa não adota o modelo de gestão proposto por Oliveira (2006), entretanto apresenta alguns componentes do mesmo. Os componentes que são mais visíveis são os que envolvem planejamento, organização e avaliação.

Como instrumento administrativo estratégico a cooperativa define sua missão e visão para que assim seja estabelecida uma direção otimizada para ser seguida.

MISSÃO: Oferecer aos nossos sócios e alunos, os melhores conhecimentos educacionais e culturais. Promover Cursos de Idiomas, Cursos de Extensão em várias áreas de conhecimento, Palestras, Assessorias Culturais e Científicas, centrados no desenvolvimento e na cidadania.

VISÃO: Ser referência Cultural, Educacional e Científica, reproduzindo o modelo Cooperativista para a sociedade, através da comunidade universitária da Universidade Federal da Paraíba.

A cooperativa apresenta um delineamento das autoridades em cada unidade organizacional, sendo definido os níveis hierárquicos e departamentos, como foi relatado pela assessora: Secretaria, coordenação dos cursos de idiomas, coordenação de marketing, assessoria de comunicação, assessoria jurídica, assessoria cooperativista, cultura e técnico científico, diretoria executiva, conselho de administração e conselho fiscal.

Quando foi perguntado qual fraqueza e qual potencialidade da CODISMA, a resposta foi clara: suas potencialidades estão relacionadas aos cursos de Idiomas com a melhor relação custo-benefício; bom relacionamento com cooperados, funcionários, professores e colaboradores, comprometimento social e profissionalismo; suas fraquezas são a pequena participação dos sócios e conselheiros no dia-a-dia da Cooperativa, falta de financiamento bancário. O que é considerado como potencialidade na cooperativa é a questão da demanda pelo aprendizado de novos idiomas, e como fraqueza, o baixo capital para investimento. 
O atual presidente Sebastião Geriz se considera um auto gestor com autoridade para tomada de decisão, e em relação as assembleias conta com a ajuda da diretoria executiva. A cooperativa não encontra dificuldades para escolha de seus representantes, prezando por profissionais capacitados e com uma vasta experiência. São sete conselheiros de administração e três conselheiros fiscais, bem como o presidente, o vice-presidente e o secretário-executivo. Sebastião Geriz considera duas principais características para um gestor de uma cooperativa, o dinamismo e a organização. Há dois princípios cooperativistas mais valorizados pela CODISMA, gestão democrática e autonomia. Todos os cooperados possuem um nível de formação suficiente para entender o que se trata o movimento cooperativista. De 0 a 10 o grau de cooperação e comprometimento entre os cooperados é sete. A cooperativa realiza uma consulta de satisfação junto aos seus clientes, por meio de questionários que são entregues no final de cada curso, para assim eles fazerem uma avaliação geral da cooperativa, do curso e dos professores. Além de reinar o espírito cooperativista de ajuda mútua.

A CODISMA enfrentou várias mudanças, desde a questão da localidade, até deixar de ser livraria para focar no ensino de idiomas, conseguindo assim, resistir a todas as mudanças pela qual passou. As turmas são limitadas. Os componentes do modelo de gestão, estão detalhados a seguir:

- Componentes diretivos: O atual presidente da CODISMA é um ótimo gestor, principalmente no que diz respeito a autoridade para tomada de decisão e supervisão de todas as atividades feitas pela diretoria executiva;

- Componentes comportamentais: Os cooperados são altamente capacitados, com um grande potencial, até pelo fato de ensinar a outras pessoas uma variedade de cursos e assim desempenham muito bem suas tarefas;

- Componentes de avaliação: Há um controle em todos os setores da cooperativa e aprimoramento das tarefas executadas;

- Componentes de mudanças: a resistência e conscientização de que necessário mudar devido novos cenário no mercado e globalização;

- Componentes tecnológicos: Sistema de informática para controle dos cursos de idiomas. Aquisição de equipamentos para otimização da produção, e novos computadores, novos Split que ajudaram na qualidade do trabalho desenvolvido;

- Componentes estruturais: Dinamismo e organização, transformação dos dados em informações. 


\section{Conclusões}

A cooperativa por ter surgido de forma emergencial, para suprir uma carência existente no Campus I da UFPB, sempre buscou aprimoramentos a organização na melhor for de gerir. Visto que designar atividades não seria fácil se não houvesse a cooperação de todos no alcance aos objetivos estabelecidos, a organização deve constituir um ambiente de cooperação de forma a ser necessário a adoção de um modelo de gestão em que venha cumprir boa parte do estatuto sempre de acordo com a realidade e as normas de regulação.

A partir dos questionários aplicados, foi possível analisar que a CODISMA enfrentou várias mudanças, desde a localidade, até deixar de ser livraria para focar no ensino de idiomas, conseguindo assim, resistir a todas as mudanças pela qual passou. Ao ser analisado o modelo de gestão adotado pela Cooperativa, observou-se que a mesma adota de maneira concreta o modelo de gestão proposto por Oliveira (2006) o qual propõe uma estrutura geral da gestão da cooperativa, dividindo-se em componentes estratégicos, estruturais, diretivos, tecnológicos, comportamentais, mudanças e avaliação.

É importante ressaltar que, com o trabalho proposto, é importante para o movimento cooperativista, porém deve-se ter um estudo mais detalhado sobre o movimento e sua forma de gestão. Por isso, faz-se necessário novas pesquisa na área pesquisada por este trabalho, estudando a gestão como um todos, o qual apresente melhor o modelo de gestão na elaboração do planejamento estratégico.

\section{Referências}

CRÚZIO, H. O. Como organizar e administrar uma cooperativa. 4 ed, Rio de Janeiro: FGV, 2005.

GIL, A.C. Métodos e Técnicas de pesquisa social. 6.ed. São Paulo: Editora ATLAS, 2008.

MATOS, A. K. V.. Cooperativismo e agronegócio. In: QUEIROZ, J. E. L.; SANTOS, M. W. B.. Direito do agronegócio. Belo Horizonte: Fórum, 2005.

OLIVEIRA, D. P. R. Manual de gestão das cooperativas: uma abordagem prática. 3 ed. São Paulo: Atlas, 2006.

ROSSÉS, F. G. et al. Sistema de gestão em cooperativas: o caso da Cooperativa Agropecuária Júlio de Castilhos. In: VII Simpósio de Excelência em Gestão e Tecnologia. Anais, 2014.

VERGARA, S. C. Projetos e relatórios de pesquisa em administração. 13. ed. São Paulo: Atlas, 2011. 
Disponível em: <http://www.ocb.org.br/site/cooperativismo/historia.asp> Acesso em: 13 de ago de 2016. 